\section{Eat, speak and smile with confidence}

Up to $86 \%$ of patients are affected by food becoming trapped under their dentures. ${ }^{1}$ This can lead to discomfort and can cause bad breath. Results have shown that Poligrip denture fixatives have the ability to seal out food particles helping to reduce gum irritation ${ }^{2}$ and lead to increased levels of confidence, comfort and chewing efficiency. ${ }^{3}$

The Poligrip range of fixatives include:

- Poligrip Flavour Free Fixative Cream

- Poligrip Ultra Denture Cream.

For further information on Poligrip and dentures, complete the Poligrip distance learner module and earn up to 1.5 hours of CPD. Find out more at www.gsk-dentalprofessionals.co.uk

1. Data on file, GSK, Canadian Quality of Life Study, 2005

2. GSK Data on File. Murphy et al., 2012

3. GSK Data on File. Durocher et al., 2008

\section{FILPOST restoration retention system - better by design}

FILPOST aids the retention of restorations by root post and core build-up. It has been engineered to be easier to place, even in difficult cases, in a faster and safer manner. There is more preserving of healthy tooth structure and it is stronger in use via its unique passive 'interlocking' system.

FILPOST is $99.8 \%$ pure titanium, biocompatible, and compatible with all dental materials. It will not corrode. It can be customised to suit the canal without risk of fracture, enabling easy insertion of multiple posts into converging canals. No drilling is required during placement thus avoiding the risk of perforation. Its anatomical shape minimises dentine removal. Retention grooves along the post, working together with retention grooves formed within the canal surface by the special Universal Groover, create a unique passive interlock that strengthens retention.

For more information, call $+44(0) 1386$ 841 864,email info@filhol.com or visit www. filhol.com.

\section{Thumble Brush}

bottles are used daily in the UK and an average family discards $40 \mathrm{~kg}$ of plastic per year. $^{1}$

It takes 500-1,000 years for plastic bags to decompose, we can therefore assume that most of the plastic ever made still exists on our planet. ${ }^{2}$ It doesn't biodegrade naturally, sunlight simply breaks it down into fragments.

This is why there is currently a 'plastic garbage patch' twice the size of Texas floating in the Pacific Ocean ${ }^{3}$ threatening our ecosystems, marine life and ultimately, us.

Practically every human being in the world is responsible for our habitual use of plastic products. In the UK alone, ${ }^{4}$ we will discard nearly 2 billion, mainly plastic, toothbrushes if current trends persist.

The Humble Brush is the world's best selling bamboo toothbrush with BPA-free, Nylon-6 bristles. Its eco-friendly 100\% biodegradable handle is made from the world's fastest growing plant. This material helps to save our planet and when one is sold here, another is given to someone in need across the globe.

\section{Protection from toothbrush contamination in a snap second}

There are more than 10 million bacteria on each of your patients' toothbrushes, according to a recent study at the University of Manchester. That means there are considerably more bacteria on a toothbrush than an average toilet seat (which has 50 bacteria per square inch) or average public lavatory floor ( 2 million bacteria per square inch).

Most people don't realise that every time they flush the loo an aerosol spray of tainted water is released, with droplets able to land as far away as 10 feet. Researchers from the University of Alabama found that brushes stored in the bathroom are contaminated with faecal matter lingering in the bristles. Toothbrushes aren't particular about whose faecal matter it is, so it's likely it won't just be patients' own which is going into their mouth every time they clean their teeth!

Fortunately, it is now possible to safeguard a toothbrush in a new way. Hot on the heels of its success in the USA, the Steripod toothbrush protector is now available in the UK. Easy to use, Steripod simply snaps onto the head of any manual or electric toothbrush, creating a protective 'pod' which physically surrounds the head and shields it from both airborne and cross contamination.

Steripod is designed to protect the brush against environmental contamination for up to three months by exuding 'active vapours' - a laboratory-formulated thymol compound which is also used in a number of mouthwashes and oral anti-septics. The product has been specially designed so that air can circulate freely which means the brush can dry naturally - contaminants require a moist atmosphere to multiply most effectively, so the drier the brush, the lower the risk of contaminants multiplying in the bristles.

Unlike other toothbrush sanitisers, Steripod is completely portable and does not require batteries or cables, meaning that it's easy to protect a brush wherever it is used; at home, on holiday, or out and about. It is also highly cost effective at $£ 4.99$ for a pack of two - providing six months of protection. For these reasons Steripod makes the ideal adjunct to any practice selling toothbrushes as it is designed to be changed at the same time as a brush at three monthly intervals.

For more information visit www.steripod.co.uk. 